\title{
Wither Agricultural DSS?
}

\author{
${ }^{1}$ Matthews K.B., ${ }^{1}$ G. Schwarz, ${ }^{1}$ K. Buchan and ${ }^{1}$ M. Rivington \\ ${ }^{1}$ Macaulay Institute, Craigiebuckler, Aberdeen, AB15 8QH. E-Mail: k.matthews@ macaulay.ac.uk
}

Keywords: DSS; Agriculture; Deliberation; Participation

\section{EXTENDED ABSTRACT}

Agricultural decision support systems (DSS) may be argued to have passed sequentially through phases of unbelief, euphoria and disappointment and to be passing into either a phase of maturity with realistic expectations of the technology or to abandonment. This paper proposes that agricultural DSS in their widest sense still have a significant role to play in shaping land use and management to meet society's changing requirements. The paper draws its conclusions from the experiences of a team developing farming-systems models and from market research into the commercial potential of such models as DSS.

Within the agricultural DSS literature several reasons have been identified for the limited impact of DSS. Two convincing explanations are that DSS can lack credibility as useful tools and that land managers are resistant to ceding agency in their decision making processes. A third factor is that DSS are trying to enter a niche market already filled by consultants and advisors with well established track records and who are well integrated within the social process of decision making. Credible efforts to overcoming these barriers have undertaken a comprehensive approach to DSS development including the testing of component models, the cost-effective provision of data and the use of participatory action research methods to develop DSS with rather than for practitioners. Despite shrewd analysis of the problems and viable strategies for overcoming them the development and deployment of DSS still faces criticism that it does not address practitioner needs and socio-political circumstances that can mean insufficient resources are available to implement best-practice.

To abandon DSS as a techno-centric dead-end would be premature. Agricultural systems remain the principal land using sectors in terms of area for much of the world and the effects of management decisions have profound effects for both rural and urban communities. There remain significant winwin improvements to resource management within farming systems that are possible and for which agricultural DSS are a suitable vehicle to influencing practice.

For rural land use it is increasingly necessary to recognise the complex trade-offs between the multiple objectives of stakeholders. This is particularly apparent where outcomes at scales above the land management unit are considered important (e.g. water quality and bio-diversity). Appropriately developed and deployed, agricultural DSS have the capacity to encapsulate scientific, practitioner and stakeholder knowledge and to present the consequences of alternative land use scenarios. They may thus inform the debate on achieving an appropriate balance between economic, social and environmental outcomes. Agricultural DSS are therefore relevant to constituencies of stakeholders beyond land managers. Technically future agricultural DSS would be likely to form part of analytical frameworks that place agricultural systems within the context of wider socioecosystems. In this role a DSS or its outputs would be deployed within social-learning processes and function as an object around which parties can debate issues. An example of using a DSS as part of an integrated assessment of EU CAP reform concludes the paper. 


\section{INTRODUCTION}

Within the literature there exists an increasingly well developed analysis of the factors that underlie the effectiveness of DSS particularly in tying the successful use of DSS back to the way in which they are developed. The paper appraises our past and current efforts in promoting the use of simulation model based farm-scale case-studies as a basis for decision support in the context of the DSS development literature. We argue that while there are models of best-practice for DSS development that can ensure their relevance and use, differences in sociopolitical circumstances and the intended outcomes of the DSS based processes probably mean that such models are not universally applicable.

\section{DEVELOPING AND DEPLOYING DSS}

Biethahn and Nissen (1995) in discussing the applications of new technologies in management present a framework that is useful in understanding the development of agricultural DSS. They argue that if one graphs expectations of an innovation against time then there is a characteristics series of phases (a modified version of their graph is presented in Figure1).

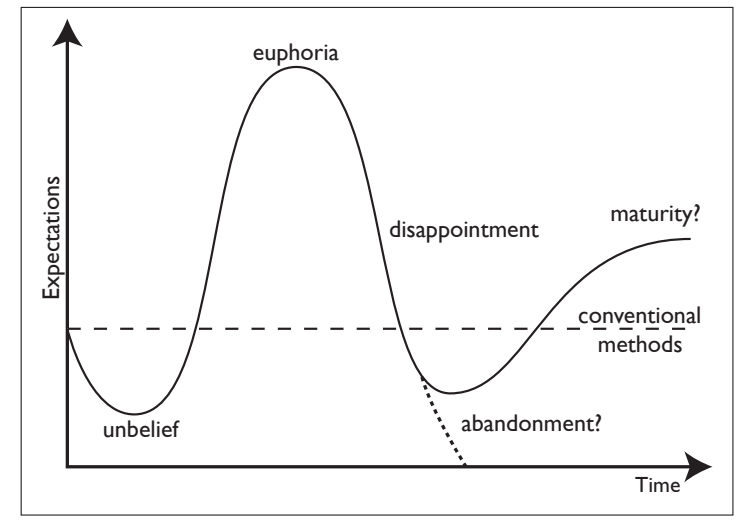

Figure 1. Expectation phases for technologies modified from (Biethahn and Nissen, 1995)

They identify four such phases that compare performance of the innovation with existing conventional practice, these are: unbelief, euphoria, disappointment and finally maturity. Within this framework we would argue that agricultural DSS are somewhere between disappointment and maturity. The Biethahn and Nissen framework may, however, be unduly optimistic in that perhaps two alternatives exist after disappointment, maturity or abandonment, and it is the latter that has been the fate for sufficient agricultural DSS to give cause for concern. While there are excellent analyses of the causes of disappointment and pathways to maturity (reviewed below) it is interesting to perhaps consider if the problems of agricultural DSS may not have their roots in the period of euphoria, particularly in technocentric development processes?

Highly persuasive analyses of the disappointment to maturity phases of agricultural DSS have been presented by Australian-based researchers. These identify the problem of implementation, that is the lack of sustained use of agricultural DSS in a way that influences practice (Carberry et al., 2002). This has been seen to have parallels in past attempts to apply DSS based on Operational Research and other approaches within industrial management (McCown, 2002). A key conclusion from this review was that it is only through the existence of a partnership between researcher and practitioner, within the research project developing the DSS, that there is much hope the plans generated by the DSS will be implemented.

This analysis was further developed by McCown (2002) in arguing that DSS should try to empower decision makers rather than forcing them to cede agency to black-box tools developed by others. This perhaps explains the relative success of ration programmes ${ }^{1}$ and accounting tools ${ }^{2}$ since these can be seen as an aid to the land manager in taking control of an activity that may have relied on others such as feed merchants or book keepers. The McCown analysis also identifies the credibility of DSS as being the key to the success of DSS. Credibility is a complex mix of social and technical aspects that requires developers to concentrate on both social networking and the quality of models/data within the DSS. In cases where these are found to be lacking it is necessary to invest resources in improving or providing them (Carberry et al., 2002). Credibility is a far more convincing explanatory property than more techno-centric explanations such as user-friendliness, simplicity or transparency.

The FARMSCAPE approach to developing and deploying agricultural DSS stands as a demonstration of what can be achieved with a participatory action research (PAR) approach, but the form of research may be a necessary yet not sufficient criteria for success. Despite PAR the project was criticised as ignoring the research needs of farmers and while that view has been rebutted, there remains concern that those farmers who adopt DSS tend to be the most innovative.

It is important that PAR not be seen as a panacea for agricultural DSS. As Jakku et al. (2004) note PAR has both practical and methodological/ethical challenges. Practically PAR is resource intensive, time consuming, can result in outcomes that are caricatured by conventional researchers as lacking

\footnotetext{
${ }^{1}$ e.g. www.rumnut.com

${ }^{2}$ e.g. www.farmplan.co.uk
} 
in rigour and results in fewer peer reviewed journal articles. These are all features that mean funding agencies are less likely to want to undertake PAR based development of DSS. Methodological and ethical challenges include the difficulty of identifying stakeholders, the raising of expectations that cannot be fulfilled and unintended negative consequences. Current research teams may also lack personnel trained in the social science theory that underpins the design and/or experience in conducting participatory approaches. Tokenism in participation is a real danger since it both destroys the good will of stakeholders and discredits PAR when projects fail to deliver.

Agricultural DSS development in the UK has also been affected by changes in the EU policy agenda which continues to move from food security and the prosperity of the agricultural sector towards multifunctional rural land use. Prosperity of the farming sector is balanced with food safety, environmental protection and sustainable development (Scottish Executive, 2001, 2002; Policy Commission on the Future of Farming and Food, 2002). While there is disagreement on the extent to which EU agricultural systems are in reality post-productivist (Wilson, 2004) policy change has had profound effects on EU research agendas.

While progress on environmental or resource management depends on the actions of individual land managers there are governance and cooperation issues at a range of scales that complicate the provision of decision support (Wilson, 2004). Where there are multiple-stakeholders, for example in strategic decision making on sustainable development or improving management of common pool resources, when there is uncertainty and disagreement on the goals to be achieved (agreeing normative values) and/or where scientific knowledge is ambiguous then context, social and cognitive factors may combine to make PAR less effective (French and Geldermann, 2005). In these circumstances the role of the DSS may be to act as a boundary object to help the communication between stakeholder groups with differing perspectives and knowledges (Jakku et al., 2004).

Even accepting the caveats above, the clear success of FARMSCAPE over other DSS (in the Australian context and relative to the UK) might have been expected to generate similar approaches within the UK where there has been considerable investment in agricultural DSS research and there is scope for win-win improvements in resource management $(£ 700$ million to $£ 1.1$ billion estimated by the Environment Agency Bragg et al. (2005)). The remainder of this paper explores, from the perspective a team involved with agricultural DSS in Scotland since 1992, some of the possible reasons why the comprehensive
FARMSCAPE approach has not yet been adopted and suggests that while the socio-political circumstances in the UK may have been be hostile to it, the essence of the approach has potential for addressing agrienvironmental issues in UK.

\section{PROJECT BACKGROUND}

The lineage of the software tools that continue to be developed by the authors goes back into the 1970 s with systems researchers working for the UK Hill Farming Research Organisation using models both as part of the research process and to communicate the outcomes to land managers. The early models had a principal focus on the prediction of off-take and growth of sheep (Armstrong and McCreath, 1985), later models also included forestry and did so in a spatially explicit manner using grids of cells (Maxwell et al., 1979). From the late 80's onwards there was a divergence in the models with semi-natural pastures tackled by one team with an emphasis on predicting the impacts of grazing on key herbage species (Hill Grazing Management Models I-III, and later HillPlan (Armstrong et al., 1997)) with the land use planning for upland farms undertaken within a second project (which perhaps significantly had no acronym), (Butcher and Sibbald, 1991). From 1993 onwards this latter model served as the basis for a land use planning DSS with development efforts focused on the integration of a geographical information system with the land use systems models (Matthews et al., 1999). The application focus during this period was on the strategic analysis of farming systems in order to assess the effects of, or responses to, policy with the client seen as the policy divisions of the then Scottish Office.

During this period there was an increasing pressure for research institutes to secure income in addition to their core government funding which was in decline. One of the options considered was to take the then prototype LADSS and to develop it commercially. There was significant debate about the nature of the commercialisation - with the debate informed by the Australian experience following a visit to CSIRO in 1995 and a workshop with a range of stakeholders in late 1997. This led to a formal market research survey, completed in early 1999. The outcomes of the market research led to a significant reappraisal of the efforts in DSS development and deployment (discussed in Section 6.).

\section{MATERIALS AND METHODOLOGY}

The market research was undertaken by Systems Insight (SI), a market research agency specialising in strategic and market assessment surveys, high tech- 
nology marketing and small business development ${ }^{3}$. SI undertook a postal survey using a questionnaire designed in consultation with the LADSS project team. The questionnaire comprised 9 questions each with check box options and space for additional comments. The distribution of 175 individuals sent questionnaires, classified by target group, is shown in Table 1 .

Table 1. Questionnaires by target group.

\begin{tabular}{lcc}
\hline Target Group & Sent & Resp-\% \\
\hline A - Local Authorities & 13 & 23 \\
C - Corporate Land Owners & 5 & 20 \\
E - Rural Estates & 9 & 55 \\
F - Financial & 10 & 0 \\
I - Interest Groups & 15 & 47 \\
L - Land Use Agents & 73 & 39 \\
P - National Parks and Forests & 8 & 62 \\
S - Supermarket owned - farms & 8 & 12 \\
U - Utilities & 27 & 25 \\
O - Other & 7 & 42 \\
\hline
\end{tabular}

The breakdown of the table is interesting as it reflects the view of the development team that the tool could not profitably be delivered to individual land managers other than those responsible either for large holdings such as estates or those responsible for multiple holdings such as land use agents. The overall response rate was $35 \%$, with significant variability around this figure for particular groups. The lower figures in some instances reflected unsuccessful targeting of appropriate individuals within larger organisations and the higher figures reflected the proactive follow ups by SI.

\section{RESULTS}

To asses the targeting of the survey the first question asked for the respondents' area of responsibility. The responses in Table 2 indicated that the respondents were broadly in the correct domain with economic, environmental and social responsibilities represented.

Table 2. Responsibilities of respondents.

\begin{tabular}{lcc}
\hline Area of responsibility & Resp & $\%$ \\
\hline Management/use advice & 55 & 90 \\
Economic impacts & 40 & 66 \\
Environmental impacts & 39 & 63 \\
Social impacts & 26 & 42 \\
Managing rural estates & 42 & 69 \\
Planning the future use & 40 & 66 \\
None of these & 2 & 3 \\
\hline
\end{tabular}

The next question established the status quo - which tools and resources were being used and is reported in

\footnotetext{
${ }^{3}$ www.systems-insight.com
}

Table 3. To some extent this met with expectations - high use of personal judgement (95\% - though numbers using only judgement were not recorded) and low use of DSS (3\%). The use of computerbased tools was significant with spread-sheets and GIS represented at 44 and 34\%. This would seem to back up McCown (2002) observation that software that is controlled by the decision maker is more popular than software that requires any degree of ceding of control. The use of external services at $34 \%$ was interesting since in nearly all cases the services were from specialist consultants, from which it was concluded that there was a market for the advice but that it was a niche already filled.

Table 3. Tools and resources being used.

\begin{tabular}{lcc}
\hline Tool/Resource & Resp & $\%$ \\
\hline Personal judgement & 58 & 95 \\
Crop yield information & 27 & 44 \\
Livestock yield information & 23 & 37 \\
Other information & 25 & 41 \\
Spreadsheets & 27 & 44 \\
Geographical Information Systems & 21 & 34 \\
Decision Support Software & 3 & 5 \\
Other Software & 10 & 16 \\
External Services & 21 & 34 \\
None of these & 1 & 2 \\
Other & 7 & 12 \\
\hline
\end{tabular}

The next question asked for the degree of satisfaction with current tools and resources. The responses (in Table 4) indicated that the vast majority of decision makers were either fairly or very satisfied with current tools and resources. This was interpreted by the market research company as meaning that any venture would face significant competition and would have to demonstrate added-value. The subsidiary question on the likelihood of reviewing tools and resources revealed that $40 \%$ would review within 1-3 years, indicating that there was perhaps more fluidity in the market than the satisfaction results alone would suggest..

Table 4. Degree of satisfaction.

\begin{tabular}{lcc}
\hline Degree of Satisfaction & Resp & $\%$ \\
\hline Very satisfied & 10 & 16 \\
Fairly satisfied & 46 & 75 \\
Fairly dissatisfied & 2 & 3 \\
Very dissatisfied & 0 & 0 \\
Dissatisfied with certain aspects & 6 & 10 \\
\hline
\end{tabular}

The questionnaire then offered a range of features to assess what would be desirable to decision makers. The most desirable feature was the visualisation of scenarios, explaining the success of computer-based mapping software, the desirability of this feature in a DSS and justifying the efforts in integrating the 
DSS and GIS software. Beyond this there was an interesting tie - between multi-criteria assessment (a feature particularly associated with DSS) and single source information provision (that perhaps explains the success of web portals, such as LaMIS ${ }^{4}$ providing single source spatial data.

Table 5. Desirability of features.

\begin{tabular}{lcc}
\hline Feature & Resp & $\%$ \\
\hline $\begin{array}{l}\text { To visualise land use scenarios as } \\
\text { computer based maps }\end{array}$ & 42 & 69 \\
$\begin{array}{l}\text { Faster decision making due to all } \\
\text { information in a single source }\end{array}$ & 37 & 60 \\
$\begin{array}{l}\text { Account for social, economic or } \\
\text { environmental criteria }\end{array}$ & 37 & 60 \\
$\begin{array}{l}\text { Quick and easy production of alter- } \\
\text { native scenarios }\end{array}$ & 36 & 59 \\
$\begin{array}{l}\text { Increased objectivity of assessment } \\
\text { Greater confidence in accuracy of }\end{array}$ & 24 & 39 \\
$\begin{array}{l}\text { assessments } \\
\text { Appraise a wide variety of crop and }\end{array}$ & 22 & 39 \\
livestock options & 36 \\
$\begin{array}{l}\text { Less fragmented decision making, } \\
\text { due to use of single tool }\end{array}$ & 20 & 32 \\
$\begin{array}{l}\text { Improved credibility of decisions } \\
\text { Other }\end{array}$ & 19 & 31 \\
None of these & 4 & 7 \\
\hline
\end{tabular}

Going beyond these general categories of improvement the questionnaire sought responses to particular capabilities some of which were under consideration for inclusion within LADSS, shown in Table 6. What is striking is that the capabilities most desired by the respondents are those, that while found in DSS, did not represent what we supposed was the added value of DSS - analysis tools. The top three are all information products or presentations of information. The desirability of conservation/bio-diversity may again reinforce the case that DSS inhabit than same niche as consultants, with ecological knowledge seemingly less easily available within organisations yet still often important for many land use decisions. The poor showing conventional single-objective optimisation $(21 \%)$ may reflect either antipathy to support tools in general (despite the use of an example of profit maximisation), or just to the concept of optimisation per se (since trade-off analysis is nearly twice as desirable (39\%). More generally SI commented that the desirability ratings for all the capabilities were such that they would not have recommended dropping any from the overall projects, but in prioritising the key features. Within the team, however, the ranking of the capabilities conflicted with an innovation led science programme.

Beyond the capabilities the survey then asked about the likely reactions to claims that a DSS could deliver

\footnotetext{
${ }^{4}$ www.lamis.org.uk
}

Table 6. Proposed capabilities.

\begin{tabular}{lcc}
\hline Capability & Resp & $\%$ \\
\hline Public designations & 41 & 67 \\
Land use plans on O.S./photo-maps & 40 & 65 \\
UK/EU grant options & 39 & 63 \\
Conservation/bio-diversity values & 37 & 60 \\
Statutory legal implications & 35 & 57 \\
Sustainability & 33 & 54 \\
Impacts on water quality & 32 & 52 \\
Profit and loss accounting & 30 & 49 \\
Profitability: land uses & 30 & 49 \\
3-D visualisation over time & 28 & 46 \\
Taxation implications & 26 & 42 \\
Investment scheduling & 24 & 39 \\
Productivity: land uses & 24 & 39 \\
Trade-offs between objectives & 24 & 39 \\
Waste management planning & 22 & 36 \\
Labour profiling & 21 & 34 \\
Suitability: land uses & 20 & 32 \\
Optimisation (single objective) & 13 & 21 \\
Other & 10 & 16 \\
\hline
\end{tabular}

against these capabilities, with the reactions shown in Table 7. From this table it is clear that while the DSS capabilities are attractive the reality was that decision makers while interested to find out more $(36 \%)$ were skeptical $(31 \%)$ and would need previous success stories to convince them (29\%). This would seem to chime with Carberry et al. (2002) experience in FARMSCAPE with interest but an initial credibility gap to be overcome. Those interested were predominantly from the agri-businesses and land-agents categories, perhaps seeking a competitive advantage. There was a significant proportion of respondents for which the DSS was not considered relevant but since there was no opportunity to say why it is difficult to interpret this result. Lastly it was interesting to note that there were a small number of respondents that had adopted DSS, and of those none had abandoned then.

Table 7. Likely responses to DSS.

\begin{tabular}{lcc}
\hline Responses to DSS & Resp & $\%$ \\
\hline Find out more & 22 & 36 \\
Want to see relevant success stories & 18 & 29 \\
Sceptical & 19 & 31 \\
Tools already developing this way & 3 & 5 \\
Not relevant & 13 & 21 \\
Already adopted & 4 & 7 \\
Tried but abandoned & 0 & 0 \\
Other & 2 & 3 \\
\hline
\end{tabular}

As a sub-question to the above the options for service delivery were queried, with software product preferred by $36 \%$, an Internet based service by $13 \%$ and a external consultancy by $10 \%$. The results of this question again emphasised the desire for control, in 
this case over the software tool itself. This preference was a serious issue for commercialisation potential since it would have involved a major commitment of resources to build and support a software package rather than delivery via the existing consultancy arm of the research institute. Whether web-based tools would now be more acceptable in 2005 would be worth investigating.

The final aspect of the survey explored the possible barriers to using the proposed DSS. The options and the responses are set out in Table 8. Here as might have been expected, cost-benefits are the key barrier, with an upper limit of $£ 5000$ and more typical values of $£ 500$ to $£ 1000$ quoted. While these values are consistent with PC software prices, they are not, other than at the upper end, consistent with the charge out rates for consultants providing professional services. This confirmed that while DSS may be seen as alternatives to consultants they crucially lack the credibility to be valued as such. The other significant barriers are the a priori knowledge that the benefits would not be significant enough (at 30\%) and that the decision maker simply does not have a budget for DSS or like software (37\%)

Table 8. Barriers to adoption.

\begin{tabular}{lcc}
\hline Barriers & Resp & $\%$ \\
\hline None - but cost-benefit decision & 26 & 43 \\
Lack of appropriate budget & 23 & 37 \\
Benefits not significant enough & 18 & 30 \\
Traditional methods preferred & 8 & 13 \\
Needs too specialised & 8 & 13 \\
System should be developed in-house & 5 & 8 \\
Decisions based on external advice & 5 & 8 \\
Other & 4 & 7 \\
Negative previous experience & 3 & 5 \\
No reason & 2 & 3 \\
Staff resistance & 0 & 0 \\
Already have a preferred system & 0 & 0 \\
\hline
\end{tabular}

The conclusions from SI were that the DSS as specified had many desirable features and little direct competition, however, indirect competition was significant, there was a high degree of satisfaction with current methods and there was a good deal of skepticism that would have to be overcome. The figures for likely income from such a venture (given the low price per unit) and the preference for software rather than services (raising the investment of development and deployment and support) combined to mean that as a commercial venture there was little reason to proceed further.

\section{REACTIONS - THE POST-DSS PERIOD?}

Subsequent reevaluation of the direction of the DSS research returned to their potential role in post-hoc and $e x$ ante policy assessment one of the core roles of the Institute and one with increasing importance since the establishment of regional government in the form the Scottish Executive. Agricultural land managers while still a key stakeholder group since $70 \%$ of land in Scotland is under agricultural management were no longer the only stakeholders that had to be considered. The policy agenda for land use was increasingly concerned with environmental protection and sustainable rural development and was thus geared to multi-functional (if not post-productivist) land use. These developments emphasised the need to be able to explore the trade-offs between multiple, non-commensurable objectives, including financial, social and environmental.

The development of the DSS continued with multiobjective land use planning tools (Matthews and Buchan, 2003) but the importance of the social aspects of decision support meant that the team increasingly looked at how the DSS could be embedded within deliberative inclusive processes (DIPs) Matthews et al. (In Press). This approach emphasised application rather than development of the tool. The DIPs involve stakeholders with differing perspectives (for example government, agency and NGO representatives) discussing an issue within a structured workshop programme. They are thus an example of reason-based debate with the aim of better informing researchers, policy makers and stakeholders. While the process may result in empowerment or change in practice this is not the primary intended outcome. The approach is illustrated in Figure 2 and is being applied to CAP reform and climate change topics (Matthews et al., In Press; Rivington et al., In Press).

Figure 2 shows the DSS used as the basis of case study analysis of particular scenarios - usually comparing the status quo with another scenario with changed circumstances - typically policy. The definition of the scenarios draws on macro-economic modelling and policy-review to provide a coherent background. Within the workshop process the results from the DSS are presented as the basis for further discussion and analysis by the delegates. Practical planning exercises have been found to be particularly useful in this regard.

The workshop deliberations are structured so as far as possible to capture the aspirations, expectations and adaptations of the delegates to the driver being examined. Less formally but equally importantly the DIPs provide an excellent opportunity to elicit practitioner knowledge - often in the form of 
heuristics that can be incorporated into formal analyses (typically restricting the set of alternative options that are considered valid). These outcomes are structured into alternative futures scenarios and serve as the basis for post hoc analysis using the DSS or are used for further macro-scale analysis.

This is less ambitious than PAR approaches but is realistic within the research teams funding structure and directly addresses its primary remit in providing advice to policy makers. This is a good example of where the socio-political circumstances and institutional arrangements mean that even where a successful development path has been demonstrated to be successful it may not be directly transferable.

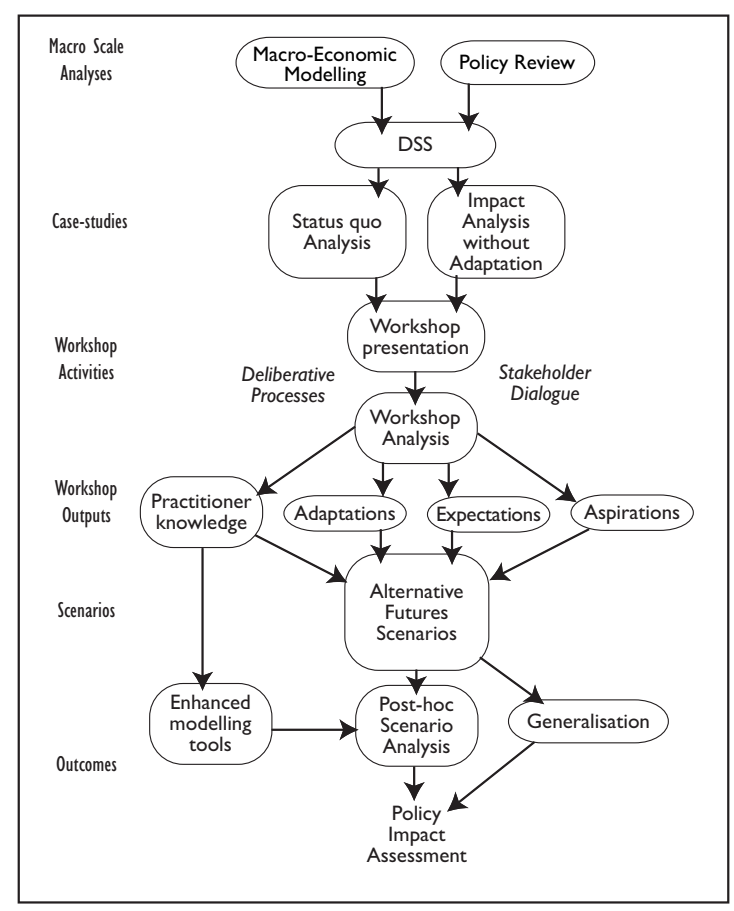

Figure 2. DSS as part of DIPs

\section{CONCLUSIONS}

From the reviews of DSS implementation, our experiences in developing land-use systems models and applying these in a DSS context and from the market research it is possible to conclude that agricultural DSS are not necessarily heading for extinction since they can be relevant to both practitioners and a wider constituency of stakeholders. For practitioners, PAR based approaches address the key issues of engagement and credibility. The operation of DSS it appears is best undertaken by researchers or consultants but with practitioners. For the wider constituencies particularly where there is debate or conflict over issues then using the DSS (or the DSS as part of a framework of tools operating at a range of scales) as a boundary object within a DIP seems to be promising since it serves both to elicit stakeholder knowledge and communicate research outcomes. In both cases the limitations on the effectiveness of the DSS may depend less on the technical or theoretical aspects of the tools but more on the institutional and socio-political environment that determines the resources available?

\section{ACKNOWLEDGMENTS}

This research is funded by the Scottish Executive Environment and Rural Affairs Department. The market research was funded by the Macaulay Development Trust. The authors would like to thank Peter Dunsmuir of System Insight Ltd.

\section{REFERENCES}

Armstrong, H., I. Gordon, S. Grant, N. Hutchings, A. Illius, J. Milne, and A. Sibbald. A model of the grazing of hill vegetation by sheep in the U.K. 1 . The prediction of vegetation biomass. Journal of Applied Ecology, 34:166-185, 1997.

Armstrong, R. and J. McCreath. The hill sheseep development programme: 1974-81. Scottish Agricultural Colleges and Hill Farming Research Organisation, 1985.

Biethahn, J. and V. Nissen. Evolutionary algorithms in management applications. Springer, Berlin, 1995.

Bragg, S., A. Inman, C. Manning, J. Pitcairn, and C. Wood. Assessment of 'Win-Win' Case Studies of Resource Management in Agriculture. Technical report, Environment Agency, March 2005.

Butcher, C. and A. Sibbald. Modelling land allocation to broad-leaved trees on upland farms. Aspects of Applied Biology, 26:239-243, 1991.

Carberry, P., Z. Hochman, R. McCown, N. Dalgliesh, M. Foale, J. H. P.L. Poulton, D. Hargreaves, S. Cawthray, N. Hillcoat, and M. Robertson. The FARMSCAPE approach to decision support: farmers', advisers, researchers' monitoring, simulation, communication and performance evaluation. Agricultural Systems, 74:141-177, 2002.

French, S. and J. Geldermann. The varied contexts of environmental decision problems and their implications for decision support. Environmental Science and Policy, 8:378-391, 2005.

Jakku, E., P. Thorburn, and C. Gambley. Sociological concepts for understanding agricultural decision support systems. In Richmond, K., editor, TASA 2004 Conference Proceedings, La Trobe University, Beechworth, 8-11 December 2004.

Matthews, K. and K. Buchan. Evaluating labour requirements within a multi-objective land use planning tool. In Post, D., editor, Integrative 
modelling of biophysical, social and economic systems for resource management solutions, volume 4, General Systems of Proceedings of the Modelling and Simulation Society of Australia and New Zealand (MODSIM), pages 1534-1539, Townsville, Australia, 2003.

Matthews, K., K. Buchan, A. Sibbald, and S. Craw. Combining deliberative and computer-based methods for multi-objective land-use planning. Agricultural Systems, In Press.

Matthews, K., A. Sibbald, and S. Craw. Implementation of a spatial decision support system for rural land use planning: integrating GIS and environmental models with search and optimisation algorithms. Computers and Electronics in Agriculture, 23:9-26, 1999.

Maxwell, T., A. Sibbald, and J. Eadie. Integration of forestry and agriculture - a model. Agricultural systems, 4(3):161-188, 1979.

McCown, R. Changing systems for supporting farmers' decisions: problems, paradigms and prospects. Agricultural Systems, 74:179-220, 2002.

McCown, R. Locating agricultural decision support systems in the troubled past and sociotechnical complexity of 'models for management'. Agricultural Systems, 74:11-25, 2002.

Policy Commission on the Future of Farming and Food. Farming and food: A sustainable future. Technical report, Cabinet Office, 2002.

Rivington, M., G. Bellocchi, K. Matthews, K. Buchan, and M. Donatelli. An integrated modelling approach to conduct multi-factorial analyses on the impacts of climate change on whole-farm systems. Environmental Modelling and Software, In Press.

Scottish Executive. A Forward Strategy for Scottish Agriculture. Technical report, Agricultural Strategy Group, 2001.

Scottish Executive. Custodians of Change. Technical report, Agriculture and Environment Working Group, 2002.

Wilson, G. The Australian Landcare movement: towards 'post-productivist' rural governance. Journal of Rural Studies, 20:461-484, 2004. 